\title{
Use of dual-mobility cup in revision hip arthroplasty reduces the risk for further dislocation: analysis of seven hundred and ninety one first-time revisions performed due to dislocation, reported to the Swedish Hip Arthroplasty Register
}

\author{
Maziar Mohaddes ${ }^{1,2}$ (1) $\cdot$ Peter Cnudde ${ }^{1,2,3}$ - Ola Rolfson ${ }^{1,2} \cdot$ Alexander Wall $^{1,2}$. \\ Johan Kärrholm ${ }^{1,2}$
}

Received: 25 November 2016 / Accepted: 19 December 2016 /Published online: 11 January 2017

(C) The Author(s) 2017. This article is published with open access at Springerlink.com

\begin{abstract}
Purpose Dislocation after total hip arthroplasty (THA) is a common reason for revision. The last decade fostered a significant increase in the use of dual-mobility cups (DMCs). Here we report our study on the short-term survival rate of a cemented DMC reported to the Swedish Hip Arthroplasty Register (SHAR) compared with other cemented designs used in first-time revision due to dislocation.

Methods During 2005-2015, 984 first-time revisions for dislocation were reported to SHAR. In 436 of these cases a cemented dual articular cup was used. During the same time period, 355 revisions performed with a standard cemented cup (femoral head size $28-36 \mathrm{~mm}$ ) were reported to the SHAR. Patients receiving a DMC were slightly older (75 years, $p=0.005$ ). Re-revision for all reasons was used as primary endpoint. We also anlaysed risk for re-revision of the acetabular component and re-revision due to dislocation. KaplanMeier implant survival and a Cox regression analyses adjusted for age and gender were performed.
\end{abstract}

Electronic supplementary material The online version of this article (doi:10.1007/s00264-016-3381-2) contains supplementary material, which is available to authorized users.

Maziar Mohaddes

Maziar.mohaddes@gmail.com

1 Department of Orthopaedics, Institute of Clinical Sciences, The Sahlgrenska Academy, University of Gothenburg, Gothenburg, Sweden

2 Swedish Hip Arthroplasty Register, Registercentrum VGR, SE-413 45 Göteborg, Sweden

3 Hywel Dda University Health Board, Llanelli, UK
Results Implant survival at 4 years for all reasons $(91 \% \pm 3.7 \%$ vs $86 \% \pm 4.1 \%, p=0.02)$, and especially for re-operation because of dislocation, favours the DMC group $(96 \% \pm 3.0 \%$ vs $92 \% \pm 3.3 \%, p=0.001)$.

Discussion Our findings indicate that use of a cemented DMC reduces the short- to mid-term risk of a second revision in first-time revisions compared with classic cup designs. Longer follow-up is needed to establish any long-term clinical advantages when DMCs are used in revisions performed due to dislocation.

Keywords Dislocation $\cdot$ Register studies $\cdot$ Revision

\section{Introduction}

According to reports from several national registries, revision hip dislocation necessitating re-revision is on the increase. The Kaiser-Permanente Register reports instability as the most common indication for re-revision (49.8\%) [1]. Bozic reports in a review of the United States National Inpatients Sample Database that $22.5 \%$ of all revisions were performed because of instability, which in this database also was the most common cause of revision [2]. In Australia, the National Joint Replacement Register Annual Report 2015 describes dislocation and instability as the reason for first revision in $25.1 \%$ and $31.1 \%$ in re-revisions [3]. In the annual report of the Swedish Hip Arthroplasty Register (SHAR) of 2015, revisions due to dislocation tended to increase and amounted to $14.6 \%$ in firsttime revisions and $25.6 \%$ in multiply revised hips [4].

Several strategies have been adopted to manage stability and prevent recurrent dislocation, with one being the use of a constrained liner. Studies [5-7] have shown unsatisfactory results after these procedures. Larger femoral-head size has 
Fig. 1 Data extraction from the Swedish Hip Arthroplasty Register (SHAR)

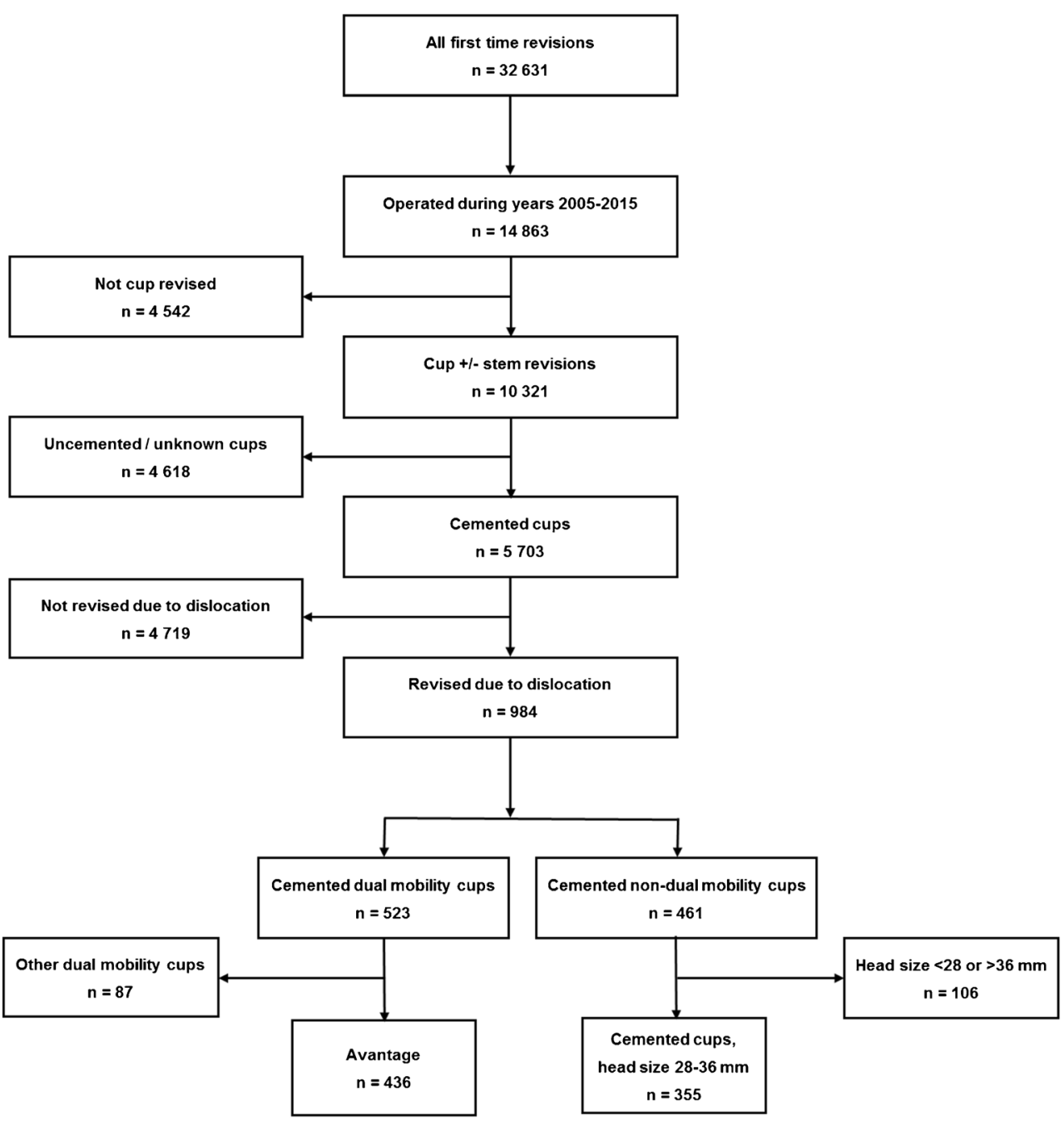

been suggested as another possible solution, but there remains uncertainty about the influence of the big head on trunnion load, possibly leading to increased risk of corrosion and the effect of thinner polyethylene when this type of articulation is used [8-10]. The biomechanical advantage of an increase in head size to avoid dislocations has, however, been studied extensively [11-13].

The dual-mobility cup (DMC) was introduced in 1974 [14], with the original intention of combining the benefits of Charnley's low-friction arthroplasty and reduced volumetric wear with the increased head size to improve stability. There are promising reports on the use of DMCs in both revision and primary surgery [15-19]. The few studies reporting on DMC outcomes following revision surgery [17, 18, 20-24] cover approximately 200 cases combined and report an early to intermediate re-revision rate due to dislocation of $<5 \%$. All previous reports analysing DMCs except one [25] are case series from single centres. Since the study by Hailer et al. [25], the use of DMCs in Sweden has increased continuously. To our knowledge, there are few studies focusing on revisions performed due to dislocation [26]. We therefore analysed outcomes of the most frequently used DMCs reported to the SHAR. Our primary aim was to compare implant survival of cemented DMCs with traditional cemented revision cups used in first-time revisions with the same indication and operated upon during the same time period.

\section{Material and methods}

In Sweden, all orthopaedic units performing revision THA report to the SHAR. The completeness of revision procedures has been reported as $90 \%$ [27]. Baseline data is completed on standard forms by a local secretary at each hospital. The operation notes are sent to the SHAR, where the register coordinators extract further data for the procedure. Data collection and validation is well accepted and has been described in SHAR annual reports. 
The first DMC used in revision surgery was reported to the SHAR in 2005. From 2005 to $2015,14,863$ first-time cup revisions with or without concomitant stem revision were reported, of which 984 were performed due to dislocation with a cemented cup. A DMC had been used in about half of the cases $(n=523)$. In most cases $(n=436)$, a cemented Avantage $^{\mathrm{TM}}$ cup (Biomet, Warsaw, IN, USA) had been inserted. The Avantage ${ }^{\mathrm{TM}}$ group (DMC) was then compared with a group operated using a standard cemented cup in which femoral head size were either 28, 32 or $36 \mathrm{~mm}$ (non-DMC, $n=355)$. In the non-DMC group, 14 different designs had been used, with the six most frequently used designs inserted in $85 \%$ of revisions. The flowchart for data extraction is illustrated in Fig. 1.

The primary outcome was any re-revision due to all causes. We also analysed cup re-revision due to all causes and any kind of re-revision performed due to dislocation. Nonparametric testing was used to compare groups. Demographic data are presented as mean \pm standard deviation (SD) or number and percentage. Kaplan-Meier statistics and log-rank test were used to compare the risk for a re-revision. Survival data are presented as percentage not re-revised and SD. Cox regression analyses adjusted for age and gender were applied. Data from the regression analysis is presented with hazard ratio (HR) and $95 \%$ confidence interval $(\mathrm{CI}) . P$ value $<0.05$ was considered as significant.

\section{Results}

Patients operated upon with a DMC were older ( $75 \pm 9$ years) compared with those operated with a non-DMC $(73 \pm$ 10 years, $p=0.005)$. There was no significant difference regarding gender between groups $(p=0.30)$. The distribution of diagnostic indications for primary surgery did not differ between groups; $25 \%$ had been operated upon for secondary arthritis in both groups $(p=0.82)$ (Table 1).

The most frequently used incision approach during revision surgery was posterolateral (DMC 65\%, non-DMC $61 \%$ ), followed by anterolateral (DMC 32\%, non-DMC $37 \%)$. There was no significant difference $(p=0.08)$ regarding type of incision between groups. In the DMC group, concomitant stem revision was less common ( $16 \%$ vs $35 \%, p<0.001$ ) and mean follow-up $(3.1 \pm 2.4)$ shorter compared with the non-DMC group $(4.4 \pm 3.1)(p<0.001)$ (Table 1). During the study period, $6.4 \%$ of the Avantage ${ }^{\mathrm{TM}}$ cups and $14 \%$ of non-DMC cups had been re-revised. The most common reason for a re-revision in the DMC group was infection $(3.4 \%$, $n=15)$, followed by dislocation $(1.6 \%, n=7)$. In the nonDMC group, 24 cases $(6.8 \%)$ were re-revised due to dislocation and $13(3.7 \%)$ due to infection (Table 1).

For up to four years there was a lower risk for re-revision due to all reasons when an Avantage ${ }^{\mathrm{TM}}$ cup had been inserted
$(91 \% \pm 3.7 \%$ vs $86 \% \pm 4.1 \%, p=0.02)$ (Fig. 2a). Re-revision cup was less common in the DMC group $(97 \% \pm 2.0 \%$ vs. $93 \% \pm 3.1 \%)(p=0.02)$ (Fig. 2b). Using re-revision due to dislocation as end-point, the Avantage ${ }^{\mathrm{TM}}$ cup performed better than a standard cemented cup $(96 \% \pm 3.0 \%$ vs $92 \% \pm 3.3 \%$, $p=0.001$ ) (Fig. 2c). After adjusting for age and gender the non-DMC group had an increased risk for revision due all causes (HR 1.7, CI 1.1-2.8) and revision due to dislocation (HR 3.6, CI 1.5-8.4). The risk for re-revision of the acetabular component for any reason was also higher for the non-DMC group (HR 2.1, CI 1.0-4.5), albeit not significant $(p=0.05)$.

\section{Discussion}

In patients with first-time revision hip arthroplasty due to dislocation, we found favourable short to mid-term implant survival for the Avantage ${ }^{\mathrm{TM}}$ DMC compared with cemented polyethylene cups up to four years. In particular, the Avantage $^{\mathrm{TM}} \mathrm{DMC}$ was associated with a considerably lower risk of re-revision due to dislocation.

In revision surgery, the type of complication leading to the first revision is also the most common reason for
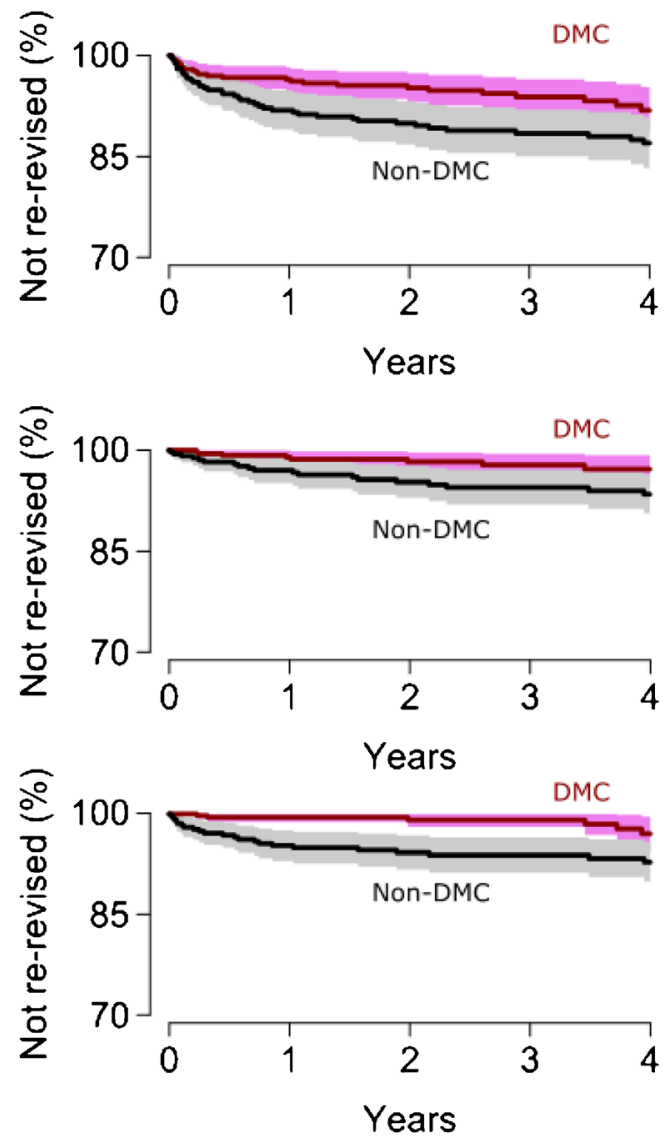

Fig. 2 Survival using Kaplan-Meier statistics. Percentage not revised due to all causes (top); percentage without re-revised cup (middle); percentage not re-revised due to dislocation (bottom) 
Table 1 Baseline demographics and surgical data

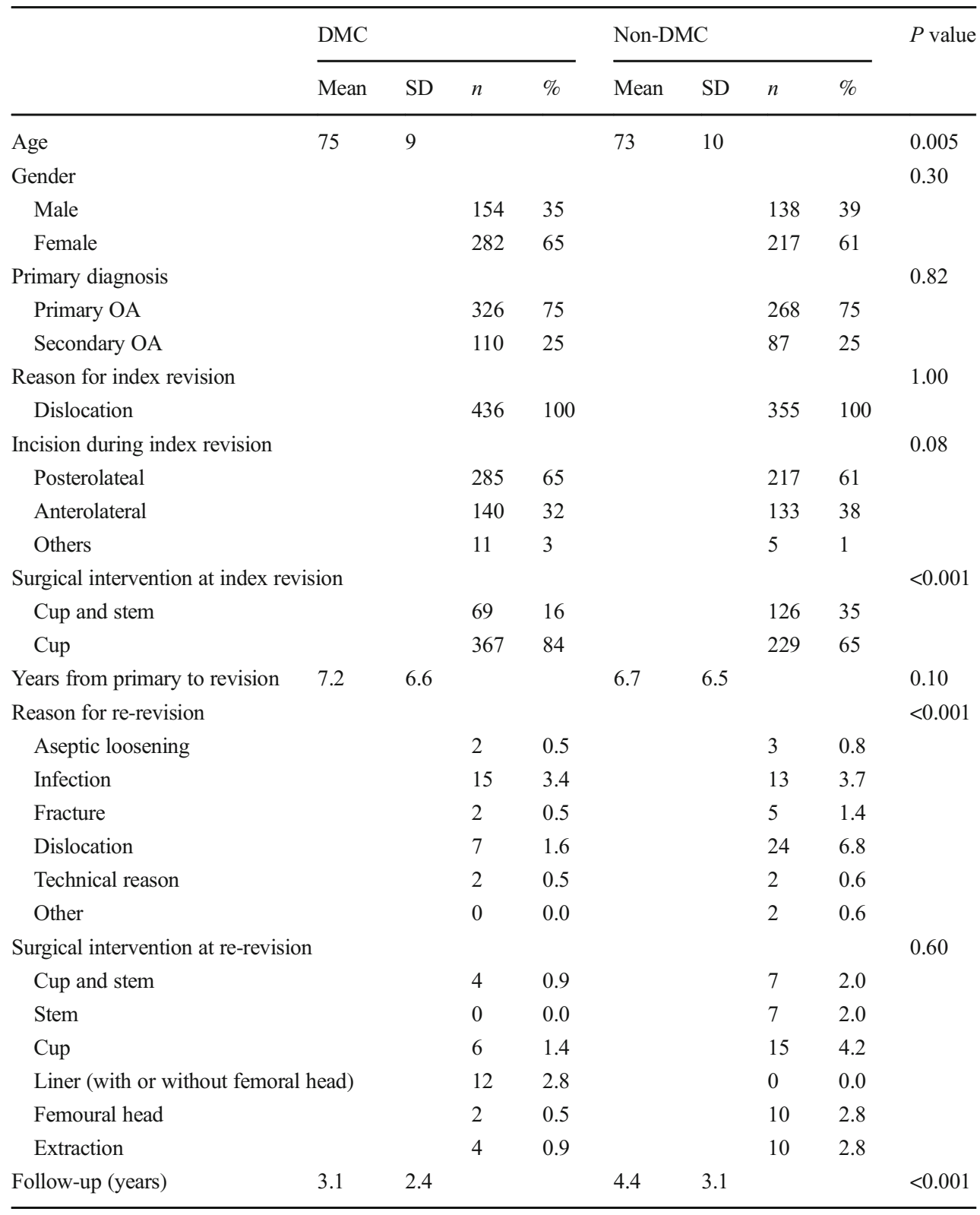

Age and time are presented as mean and standard deviation (SD). All other data are presented as numbers and percentages. $P$ value is from nonparametric testing

$D M C$ dual-mobility cup, $O A$ osteoarthritis further revision surgeries [4]. Besides periprosthetic infection, dislocation is a leading cause of early failure following primary THA. The aetiology of dislocation is often multifactorial; patient factors such as neurological comorbidities and soft tissue condition around the hip, as well as factors related to surgical technique, implant positioning and implant characteristics may all individually or in combination explain dislocation [28]. However, how the different factors contribute in any given patient with instability may be cumbersome to determine. The main challenge in revision due to dislocation is to achieve a stable situation based on careful preoperative planning and optimum surgical technique. Choice of an implant with reliable protective effect against dislocation is also desirable, as long as this implant is not associated with other negative effects such as increased wear or increased risk of loosening.

The Avantage ${ }^{\mathrm{TM}}$ DMC concept, with its large mobile polyethylene liner, constrained head, irregular-shaped shell design to reduce impingement and high jump distance, theoretically protects from dislocation. Many retrospective studies with limited numbers show acceptable dislocation rates in both primary and revision hip replacement using DMC [29]. To our knowledge, there are no 
randomised trials providing thorough evidence of the efficacy of DMC to prevent instability. Remaining concerns about fixation in cemented metal-backed polyethylene cups and speculation regarding increased polyethylene wear add to the uncertainty of the long-term outcomes $[30,31]$.

Guyen et al. investigated the DMC in unstable revision hip arthroplasty [18]. They retrospectively reviewed 54 patients with revision due to instability using DMC and reported no further revision due to dislocation at a mean follow-up of four years. In an analysis of 228 revisions performed due to dislocation, where a DMC had been used the authors report a survival of $99 \%$ at two years with re-revision due to dislocation as the endpoint [25]. Saragaglia et al. [32] analysed a group of 29 revisions performed due to dislocation. With a mean followup of four years, only one patient (3.6\%) had redislocated.

In our analysis, including 436 revisions performed with a DMC cup, cup with revision due to dislocation at four years was $96 \%$. Regardless of outcome being studied, survival for DMC cups was higher than when a traditional cemented cup was used.

We acknowledge that our study has some limitations. The mean follow-up in the DMC and control groups were only 3.1 and 4.4 years, respectively. However, dislocation is a complication that generally occurs early after revision surgery, suggesting a sufficient follow-up period for the primary outcome measure. A source of bias is the possible nonrandom variation of individual surgeons' preferences to use cemented DMC or cemented non-DMC revision implants. Patient-related factors, such as severity of instability pre-operatively, anatomical capacity to accommodate a cup of desired inner diameter, possible differences in bone loss severity between groups and need for bone grafting may all contribute to bias that cannot be controlled for in this study. Finally, our results are only valid for one single design. There are no studies indicating that the protective effect of a DMC cup should vary between different manufacturers and designs. In SHAR, there are reports on other DMC designs, both cemented and uncemented, but so far, numbers and follow-up are limited, not allowing further analysis of these designs.

The strengths of this observational study are the relatively large number of cases included and the use of high-quality, continuously validated data of the SHAR. The results are representative on a national level comparing two different acetabular revision concepts used in routine health care performed by different surgeons at many different hospitals.

In conclusion, cemented DMC used in hip revision surgery due to dislocation appear to protect from further dislocations. Although long-term overall implant survival is not known, these favourable short- to mid-term results suggest an increased use of DMC in acetabular revisions for dislocation when the cemented technique is an option.
Acknowledgements We thank the coordinators of the Swedish Hip Arthroplasty Register for their efforts in collecting and validating data in the SHAR.

\section{Compliance with ethical standards}

Conflict of interest The last author has received institutional research support from ZimmerBiomet, Lima Corporation, Depuy and Link Sweden.

Funding None.

Ethical approval The study was approved by the regional ethical board in Gothenburg, Sweden, 623-16, 4/8/2016.

Informed consent Informed consent was obtained from all individual participants included in the study.

Open Access This article is distributed under the terms of the Creative Commons Attribution 4.0 International License (http:// creativecommons.org/licenses/by/4.0/), which permits unrestricted use, distribution, and reproduction in any medium, provided you give appropriate credit to the original author(s) and the source, provide a link to the Creative Commons license, and indicate if changes were made.

\section{References}

1. Khatod M, Cafri G, Namba RS, Inacio MC, Paxton EW (2014) Risk factors for total hip arthroplasty aseptic revision. J Arthroplasty 29(7):1412-7

2. Bozic KJ, Kurtz SM, Lau E, Ong K, Vail TP, Berry DJ (2009) The epidemiology of revision total hip arthroplasty in the United States. J Bone Joint Surg Am 91(1):128-33

3. Australian Orthopaedic Association National Joint Replacement Registry. Annual Report. Adelaide:AOA; 2015. 2015 [cited 2016 31 October 2016].

4. Garellick, G., Kärrholm, J., Lindahl, H., Malchau, H., Rogmark, C., Rolfson, O. The Swedish Hip Arthroplasty Register, Annual Report 2014. 2015 [cited 201631 October 2016].

5. Andersen AV, Kjersgaard AG, Solgaard S (2013) Trilogyconstrained acetabular component for recurrent dislocation. ISRN Orthop, 2013: 629201

6. Guyen O, Lewallen DG, Cabanela ME (2008) Modes of failure of Osteonics constrained tripolar implants: a retrospective analysis of forty-three failed implants. J Bone Joint Surg Am 90(7):1553-60

7. Berend KR, Lombardi AV Jr, Mallory TH, Adams JB, Russell JH, Groseth KL (2005) The long-term outcome of 755 consecutive constrained acetabular components in total hip arthroplasty examining the successes and failures. J Arthroplasty 20(7 Suppl 3):93102

8. Cooper HJ, Della Valle CJ, Berger RA, Tetreault M, Paprosky WG, Sporer SM, Jacobs JJ (2012) Corrosion at the head-neck taper as a cause for adverse local tissue reactions after total hip arthroplasty. $\mathrm{J}$ Bone Joint Surg Am 94(18):1655-61

9. Duffy GP, Wannomae KK, Rowell SL, Muratoglu OK (2009) Fracture of a cross-linked polyethylene liner due to impingement. J Arthroplasty 24(1):158 e15-9

10. Burroughs BR, Hallstrom B, Golladay GJ, Hoeffel D, Harris WH (2005) Range of motion and stability in total hip arthroplasty with 28-, 32-, 38-, and 44-mm femoral head sizes. J Arthroplasty 20(1): $11-9$ 
11. Berry DJ, von Knoch M, Schleck CD, Harmsen WS (2005) Effect of femoral head diameter and operative approach on risk of dislocation after primary total hip arthroplasty. J Bone Joint Surg Am 87(11):2456-63

12. Jameson SS, Lees D, James P, Serrano-Pedraza I, Partington PF, Muller SD, Meek RM, Reed MR (2011) Lower rates of dislocation with increased femoral head size after primary total hip replacement: a five-year analysis of NHS patients in England. J Bone Joint Surg (Br) 93(7):876-80

13. Garbuz DS, Masri BA, Duncan CP, Greidanus NV, Bohm ER, Petrak MJ, Della Valle CJ, Gross AE (2012) The Frank Stinchfield Award: Dislocation in revision THA: do large heads (36 and $40 \mathrm{~mm}$ ) result in reduced dislocation rates in a randomized clinical trial? Clin Orthop Relat Res 470(2):351-6

14. Farizon F, de Lavison R, Azoulai JJ, Bousquet G (1998) Results with a cementless alumina-coated cup with dual mobility - A twelve-year follow-up study. Int Orthop 22(4):219-224

15. Langlais FL, Gaucher F, Musset T, Chaix O (2008) Dual mobility cemented cups have low dislocation rates in THA revisions. Clin Orthop Relat Res 466:389-395

16. Leiber-Wackenheim F, Brunschweiler B, Ehlinger M, Gabriona A, Mertla P (2011) Treatment of recurrent THR dislocation using of a cementless dual-mobility cup: A 59 cases series with a mean 8 years' follow-up. Elsevier, 97: 8-13

17. Hamadouche M, Biau DJ, Huten D, Musset T, Gaucher F (2010) The use of a cemented dual mobility socket to treat recurrent dislocation. Clin Orthop Relat Res 468:3248-3254

18. Guyen O, Pibarot V, Vaz G, Chevillotte C, Béjui-Hugues J (2009) Use of a Dual Mobility Socket to Manage Total Hip Arthroplasty Instability. Clin Orthop Relat Res 467:465-472

19. Caton JH, Prudhon JL, Ferreira A, Aslanian T, Verdier R (2014) A comparative and retrospective study of three hundred and twenty primary Charnley type hip replacements with a minimum follow up of ten years to assess wether a dual mobility cup has a decreased dislocation risk. Int Orthop 38(6):1125-1129

20. Leiber-Wackenheim F, Brunschweiler B, Ehlinger M, Gabrion A, Mertl P (2011) Treatment of recurrent THR dislocation using of a cementless dual-mobility cup: a 59 cases series with a mean 8 years' follow-up. Orthop Traumatol Surg Res 97(1):8-13

21. van Heumen M, Heesterbeek PJ, Swierstra BA, Van Hellemondt GG, Goosen JH (2015) Dual mobility acetabular component in revision total hip arthroplasty for persistent dislocation: no dislocations in 50 hips after 1-5 years. J Orthop Traumatol 16(1):15-20

22. Jakobsen T, Kappel A, Hansen F, Krarup N (2014) The dislocating hip replacement - revision with a dual mobility cup in 56 consecutive patients. Open Orthop J 8:268-71

23. Philippot R, Adam P, Reckhaus M, Delangle F, Verdot F-X, Curvale G, Farizon F (2009) Prevention of dislocation in total hip revision surgery using a dual mobility design. Orthop Traumatol Surg Res 95(6):407-413

24. Prudhon JL, Steffann F, Ferreira A, Verdier R, Aslanian T, Caton J (2014) Cementless dual-mobility cup in total hip arthroplasty revision. Int Orthop 38(12):2463-2468

25. Hailer NP, Weiss RJ, Stark A, Kärrholm J (2012) Dual-mobility cups for revision due to instability are associated with a low rate of re-revisions due to dislocation: 228 patients from the Swedish Hip Arthroplasty Register. Acta Orthop 83(6):566-571

26. Leclercq S, El Blidi S, Aubriot J (1995) Traitement de la luxation récidivante de prothèse totale de hanche par le cotyle de Bousquet. A propos de 13 cas. Rev Chir Orthop Reparatrice Appar Mot 81(5): 389-394

27. Soderman $P$, Malchau H, Herberts $P$, Zügner R, Regnér H, Garellick G (2001) Outcome after total hip arthroplasty: Part II. Diseasespecific follow-up and the Swedish National Total Hip Arthroplasty Register. Acta Orthop 72(2):113-119

28. Timperley AJ, Biau D, Chew D, Whitehouse SL (2016) Dislocation after total hip replacement: there is no such thing as a safe zone for socket placement with the posterior approach. Hip Int

29. Grazioli A, Ek ETH, Rüdiger HA (2012) Biomechanical concept and clinical outcome of dual mobility cups. Int Orthop 36(12): 2411-2418

30. Ritter MA (1995) The Cemented Acetabular Component of a Total Hip Replacement: All Polyethylene Versus Metal Backing. Clin Orthop Relat Res 311:69-75

31. Peraldi P, Vandenbussche E, Augereau B (1996) Bad clinical results of cemented caps with metal-backed acetabular components. 124 cases with 21 months follow-up. Rev Chir Orthop Reparatrice Appar Mot 83(6):561-565

32. Saragaglia D, Ruatti S, Refaie R (2013) Relevance of a press-fit dual mobility cup to deal with recurrent dislocation of conventional total hip arthroplasty: a 29-case series. Eur J Orthop Surg Traumatol 23(4):431-436 